interposed between the wall plug and the sledge coil, or else the latter may be fused or damaged. Instead of the ordinary electrodes two basins of water or at least large wet sponges are necessary. With a small wooden wash-tub a most agreeable and effective electric sitz bath can be given in cases of lumbago and sciatica. The ends of the wires may be fastened to strips of copper and hung inside the tub, care keing taken that they reach below the surface of the water and do not touch the patient. Metal baths are difficult to use, and even if japanned the results are very uncertain, so that earthenware or wood can alone be recommended. The chief point to remember is that care must be used not to touch the apparatus in the region of the primary current, e.g., the lamp wires, or near the hammer, lest we get a shock from the primary current.

Some of my nurses who were standing on a wet floor were much astonished to get a shock when fastening on the wires from the lamp to the sledge, although the switch on the wall was turned off. This is easy of explanation, for the switch only cuts off one wire, and the remaining one carried the current to earth through the nurse. Careful attention to details of this kind is necessary, if unpleasant results are to be avoided, and especially should no patient be allowed to get into a bath alone or before it has been tested by dipping both hands into it as far apart as possible, the maximum current to be used having been first turned on. If all is satisfactory the current should then be turned down for the patient to get in and slowly raised afterwards. No patient should be left alone when taking a bath.

$$
1 \text { Archives d'Electrotherapie. }
$$

(To be continued.)

\section{THE PREVENTION OF TYPHOID FEVER IN ARMIES.}

THE long.expected discussion upon the proposals made by Dr. Leigh Canney for the prevention of typhoid in armies by providing the troops with boiled water took place at the last meeting of the Medical Society. Dr. Canney set forth his now wellknown views, holding that it was highly improbable that dust or flies could give rise to an epidemic of typhoid fever in a camp with properly organised latrines, that the theory of convection could not be maintained, and that the main avenue of introduction of the bacillus into the human body was the water supply. He further said that the spread of the disease by the subsidiary channels-flies, dust, and contact-only became factors of any importance under conditions of the grossest neglect of sanitation. In the discussion which followed, however, much doubt was thrown upon Dr. Leigh Canney's main conclusions, at any rate so far as concerned the exclusive influence of water in disseminating the disease. Everyone, of course, admitted the effectiveness of polluted water as a means of distributing typhoid infection, but most of the speakers differed from him in regard to the exclusive or dominant influence of water supply in the circumstances of warfare, to which Dr. Canney's remarks had been specially directed.

Dr. C. Childs said that it was admitted on all sides that typhoid infection might be conveyed through various channels, but he took exception to Dr. Canney's statement that if water avenues were closed all the others might be neglected. Many out- breaks were undoubtedly due to water convection, but endemic and sporadic cases could be better explained in other ways. Direct infection was, he thought, more common than was generally suspected. He criticised the data drawn from Egypt and South Africa upon which Dr. Canney had based his conclusions, and held that while water was undoubtedly one, perhaps the chief, means of conveying the infection, dust, flies, and general insanitary conditions were also potent factors.

Dr. Edward Squire pointed out that in the campaign in Suakin the entire water taken by the troops was distilled, and thus thoroughly disinfected, yet the incidence of enteric fever was very considerable.

Major R. H. Firth, R.A.M.C., drew attention to the very different conditions which existed in the Army, especially when in the field, compared with those of civil life, holding that Dr. Canney took too little account of dust, flies, and other means of conveying the disease. It was in tent life, when the men were very closely packed together, that the greatest danger arose. He also insisted upon a very important point, namely, the necessity of correct and trustworthy methods of disposing of excreta being practised by the troops in time of peace, for, as things are, he said, in peace time the disposal of the excreta was performed by contractors, and consequently as soon as the soldiers took the field they were at a loss to know what to do with them.

As emphasising the importance of a pure water supply, which we suppose no one doubts, the remarks of Surgeon-General Sir A. C. de Renzy were interesting, in that he drew attention again to the enormous reduction in the death-rate from typhoid fever which had taken place at Fort William, Calcutta, at Peshawur, and other places on the introduction of a pure water supply. It is to be noted, however, that great as was the effect of the change in the water supply at these places-proving that the bad water had been entirely responsible for a large portion of the disease which had existedstill the fact that there was a considerable residuum of cases upon which the new water supply had no effect whatever - an irreducible minimum soon being reached beyond which no improvement took placewas an equally definite proof that the water was not responsible for the whole of the mischief, and that a considerable proportion of the cases occurred quite independently of water-borne infection. The general opinion seems to be-the common-sense one-that to obtain protection from typhoid fever very greatly improved methods of general sanitation must be insisted upon in military camps, and that among other means to health a supply of pure water must be provided. Indeed, this may be taken as the final outcome of the discussion, for Dr. Canney himself has now added to his demand for a "water section" one for a "pioneer section" to superintend the management of soil, the establishment of latrines, and so on, and holds that " if the water supply were in the first place protected, and the excreta disinfected, then the risk of epidemics in sanitary camps might be disregarded." Which goes without saying.

\section{MALIGNANT ADENOMA OF THE KIDNEY.}

A REMARKABLE case, and one which must serve to brighten the gloomy prognosis which hangs over all cases of tumour of the kidney in children, was shown 
to the last meeting of the Clinical Society by Dr. J. D. Malcolm. The patient, from whom in November, 1892, he had removed a malignant adenoma of the right kidney, he now exhibited. She was now 11 years and 10 months old, and enjoyed good health, although she was rather paler than her brothers and sisters. The kidney with the tumour attached, which he had removed ten years ago, was preserved in the Museum of the Royal College of Surgeons. All the capsule of the kidney and some enlarged glands on the renal vessels were removed. $\mathrm{Mr}$. Targett had examined the tumour and described it as "malignant adenoma." Only two cases in which tumours of the kidney had been removed from children who had survived the operation for two years, were known to Mr. Malcolm. Both of these had been operated on by Dr. Abbé, of New York, but in one of these, three and a half years after the operation, sarcoma developed in the opposite kidney, and life was rapidly destroyed. The President, in congratulating Mr. Malcolm on the case, said that he could not recall a single instance in which malignant disease of the kidney in a child had been operated on with permanent success.

\section{EXOPHTHALMIC GOITRE.}

THE drift of the discussion on exophthalmic goitre which tcok place at the last meeting of the Royal Medical and Chirurgical Society, was to suggest a greater hopefulness in the prognosis of this disorder than some have been willing to admit. Dr. George R. Murray, of Newcastle, related the results of his observation of 120 cases, of which 110 had occurred in women and only 10 in men. The onset of the disease being nearly always insidious the age of onset was difficult to determine, but the disease had most frequently started in the earlier decades of life, the greatest liability to it being between 15 and 35 years of age. In several cases brothers or sisters of the patients had suffered from the same malady, but there was no history of goitre in either parent of any case. As to antecedent conditions, it appeared that sudden and prolonged grief, or events producing powerful emotions, had been the exciting causes in some of the cases. The first symptom noted was generally the goitre, but in 19 cases it was palpitation, while in three of the cases there was no thyroid enlargement. In all the cases the pulse rate was increased, ranging from 90 up to 200 per minute ; in 66 cases it was between 120 and 150, but there was great variation in individual cases from time to time. In 33 of the cases no exophthalmos was present, and in three, such as had existed disappeared. The course of the disease was variable. In one case it lasted only nine months, and ended in recovery ; in another death occurred within a year. In a considerable number of cases practical recovery took place, although usually some relic of the condition persisted. In no case did myxœdema ensue. As to treatment thyroid gland was harmful, but thymus and supra-renal extract had proved useful. In severe cases rest in bed for three or four weeks was essential, and if there were much wasting Weir-Mitchell treatment was indicated. For less severe cases a quiet life with much time spent in the open air was best. Gentle Faradism for an hour night and morning was useful, and should be carried on for several months. Convallaria had proved more effectual than other cardiac tonics in lowering the pulse rate. Bromides were useful for the accompanying nervousness, and arsenic in moderate doses gave good results in almost all cases.

Dr. Hale White pointed out that there was some relation between this disease and rheumatic tendencies, and that there was also a close association with mental disease. As to treatment, belladonna was rarely if ever useful, neither were thymus or suprarenal tablets. The best treatment was probably hygienic with quietness.

Dr. Ewart thought that the disease depended upon a chronic intoxication in susceptible subjects, the diarrhœa which was so often seen, although partly paralytic, was probably often toxic or fermentive, while even the thyroid changes were probably the result of a toxic influence.

In reference to the question of fright or anxiety being causes of the disease Dr. Rolleston mentioned the increased prevalence of the cases since the war, and described the case of a yeoman who developed symptoms after serving in South Africa. $\mathrm{He}$ thought the prognosis was not very bad, as fatal cases were in his experience rare.

\section{Progress in Diseases OF THE BLOOD.}

\section{(Corcluded trom page 82.)}

Pernicious Anæmia.-W. Hunter ${ }^{9}$ has examined microscopically sections from seven cases showing the presence of (1) a septic infection of the mouth, stomach and intestines, (2) a specific infection of the tongue marked by a form of glossitis, and he records the symptoms from 18 others. He insists that the onset of the disease is not preceded by any external cause sufficient to explain the anæmia, that with severe blood changes we find four groups of symptoms - anæmia, hæmolysis with deposits in the liver and spleen, gastro-intestinal sepsis, and a toxic state. The hæmolysis does not occur in other anæmias, and is not due to ordinary sepsis. The peculiar form of glossitis was found in every one of the 25 cases, the mucosa being so thinned that the lymphatics were exposed, and from them pure cultures of strepto- coccus longus were obtained. A. Goodall, ${ }^{10}$ in a discussion of nine cases, notes that dental caries is not always present, and that the teeth of four of his patients were good. Hæmorrhages, urobilinuria, and respiratory troubles point to a grave prognosis. The average number of red cells in 11 cases when first seen was $1,049,000$, and if a further reduction during the next fortnight took place there was soon a fatal ending; if they rose, a remission or chronic state followed. The red cells take up basic stains more readily than in health, and with a double stain will be purple instead of red. Megaloblasts, too, are often more numerous than normoblasts, a state which is hardly ever seen in other diseases. Lymphocytes are increased, and number about 50 per cent. of the white cells, but when febrile conditions 